\title{
How Do We Introduce the Arrhenius Pre-Exponential Factor (A) to Graduate Students?
}

\author{
Vandanapu Jagannadham
}

Department of Chemistry, Osmania University, Hyderabad, India.

Email: jagannadham1950@yahoo.com

Received May 21 ${ }^{\text {st }}, 2010$; revised July $2^{\text {nd }}, 2010$; accepted July $19^{\text {th }}, 2010$.

\begin{abstract}
A simple and easy understanding of Arrhenius pre-exponential factor $(A)$ is described in this article for a graduate class-room lecture.
\end{abstract}

Keywords: Arrhenius Factor, Pre-Exponential Factor, Frequency Factor, Collision Number, Collision Frequency

\section{Introduction}

In chemical kinetics, the pre-exponential factor or A factor is the pre-exponential constant in the Arrhenius equation, an empirical relationship between temperature and rate coefficient. It is usually designated by A when determined from experiment, while $\mathrm{Z}$ is usually left for collision frequency. For a first order reaction it has units of $\mathrm{s}^{-1}$, for that reason it is often called frequency factor.

In short, the Arrhenius equation gives "the dependence of the rate constant $k$ of chemical reactions on the temperature $\mathrm{T}$ (in Kelvin) and activation energy $\mathrm{Ea}$ ", as shown below:

$$
k=\mathrm{Ae}^{-\mathrm{Ea} / \mathrm{RT}}
$$

where A is the pre-exponential factor or simply the pre-factor and $\mathrm{R}$ is the gas constant. The units of the pre-exponential factor are identical to those of the rate constant and will vary depending on the order of the reaction. If the reaction is first order it has the units $\mathrm{s}^{-1}$, and for that reason it is often called the frequency factor or attempt frequency of the reaction. When the activation energy is given in molecular units, instead of molar units, e.g. joules per molecule instead of joules per mole, the Boltzmann constant is used instead of the gas constant. It can be seen that either increasing the temperature or decreasing the activation energy (for example through the use of catalysts) will result in an increase in rate of reaction.

Given the small temperature range in which kinetic studies are carried, it is reasonable to approximate the activation energy as being independent of the temperature. Similarly, under a wide range of practical condi- tions, the weak temperature dependence of the pre-exponential factor is negligible compared to the temperature dependence of the factor; except in the case of "barrier less" or diffusion-limited reactions, in which case the pre-exponential factor is dominant and is directly observable.

\section{The Interpretation of Pre-Exponential Factor in the Arrhenius Equation}

So far we have talked if not exhaustively but enough about the pre-exponential factor for a M. Sc. Class-room. So what is really the pre-exponential factor in the Arrhenius equation? Did anybody think of its value with change in temperature? Or did anybody guess its value at infinite temperature? It can be said as "It is nothing but $k$ at infinite temperature or it is $k$ of a reaction with zero activation energy (barrier less)". So in either way $k$ will be very large, more so it is a rate constant close to diffusion limit $\left(5 \times 10^{9} \mathrm{M}^{-1} \mathrm{sec}^{-1}\right)$. This can be seen as in the following by simple mathematics. On right hand side of the Arrhenius equation $E_{a}$ and $T$ are the only variables whereas $\mathrm{A}$ and $\mathrm{R}$ are constants. $k$ will be equal to $\mathrm{A}$ when the exponential factor becomes equal to one.

Therefore $\exp \left(-\mathrm{E}_{\mathrm{a}} / \mathrm{RT}\right)=1$, which leads to

$$
-\mathrm{E}_{\mathrm{a}} / \mathrm{RT}=0
$$

Hence $\mathrm{T}$ should become infinite. Or the other possibility is $\mathrm{E}_{\mathrm{a}}$ should be zero or the reaction should be "barrier less".

\section{Evaluation of $A$}

In the first case: To get $\mathrm{A}$ it is necessary to evaluate $k$ experimentally, in which it is not possible to determine 
such a large rate constant at infinite temperature because one cannot maintain or achieve infinite temperature. Instead one can determine the $k$ at different temperatures and get A from the antilogarithm of the intercept of the Arrhenius plot (plot of $\ln k$ or $\log k$ versus $1 / \mathrm{T}$ ).

In the second case: One can use fast reaction kinetic techniques like stopped flow methods, T-jump or P-jump methods, laser flash photolysis, and pulse radiolysis.

In the third case: Proceed to evaluate by calculation [1] assuming the atoms or molecules as Hard-Spheres as pointed out by Max Trautz - 1916 [2] and W. C. McC. Lewis - 1918 [3]. The formulation given by these people was purely based on simple version of the kinetic theory of gases in which the molecules were treated as hard spheres.

The final equation obtained was

$$
Z_{A A}=2 d^{2} N_{A}^{2}\left(\frac{\pi k_{B} T}{m}\right)^{\frac{1}{2}}
$$

and if the gas contains two types of molecules say A and $\mathrm{B}$ and where ' $\mu$ ' is reduced mass, the equation obtained was

$$
Z_{A B}=N_{A} N_{B} d^{2}\left(\frac{8 \pi k_{B} T}{\mu}\right)^{\frac{1}{2}}
$$

Lewis [3] applied this equation to the decomposition of HI.

$$
2 \mathrm{HI} \rightarrow \mathrm{H}_{2}+\mathrm{I}_{2}
$$

He obtained a value of $5.5 \times 10^{10} \mathrm{~mole}^{-1} \mathrm{sec}^{-1}$ for ' $\mathrm{A}$ ', both by experiment and by calculation. This clearly shows that the theory put forward by Trautz and Lewis assuming the molecules as hard spheres and neglecting the slight variation of ' $A$ ' with temperature in good agreement with each other.

In Table 1, $\log$ A values are given for some gas phase reactions [4]. It is clear that the calculated values are all
Table 1. Some gas phase reactions and their observed and calculated logarithmic values of Arrhenius frequency factors (A).

\begin{tabular}{lcc}
\hline \multirow{2}{*}{ Reaction } & \multicolumn{2}{c}{ Log A, mole-1 sec-1 } \\
\cline { 2 - 3 } & Observed & $\begin{array}{l}\text { Calculated by simple } \\
\text { collision theory }\end{array}$ \\
\hline $\mathrm{NO}+\mathrm{O}_{3} \rightarrow \mathrm{NO}_{2}+\mathrm{O}_{2}$ & 11.9 & 13.7 \\
$\mathrm{NO}_{2}+\mathrm{F}_{2} \rightarrow \mathrm{NO}_{2} \mathrm{~F}+\mathrm{F}$ & 12.2 & 13.8 \\
$\mathrm{NO}_{2}+\mathrm{CO} \rightarrow \mathrm{NO}+\mathrm{CO}_{2}$ & 13.1 & 13.6 \\
$2 \mathrm{ClO} \rightarrow \mathrm{Cl}_{2}+\mathrm{O} 2$ & 10.8 & 13.4 \\
$2 \mathrm{NOCl} \rightarrow 2 \mathrm{NO}+\mathrm{Cl}_{2}$ & 13.0 & 13.8 \\
$\mathrm{NO}+\mathrm{Cl}_{2} \rightarrow \mathrm{NOCl}+\mathrm{Cl}$ & 12.6 & 14.0 \\
\hline
\end{tabular}

close to 14 which may be due to the fact that the over simplification of the assumption that the molecules were assumed to be hard-spheres and to have the same molecular diameter. The observed values were smaller than those of the calculated ones. The reason is that the steric factors, which are the ratios of the observed values to those calculated ones, vary from $10^{-1}$ to $10^{-3}$. The low steric factors are attributed to the losses of rotational freedom during the formation of the activated complex.

\section{REFERENCES}

[1] K. J. Laidler, "Chemical Kinetics," 2nd Edition, Tata-McGraw Hill, Inc., New York, 1973, pp 63-64.

[2] M. Trautz and Z. Anorg, "Evaluation of Arrhenius Frequency Factor (A) by Simple Collision Theory," Chemistry, Vol. 96, No. 1, 1916.

[3] W. C. M. Lewis, "Evaluation of Arrhenius Frequency Factor (A) by Simple Collision Theory Assuming Atoms and Molecules As Hard Spheres," Journal of Chemistry Socialist, Vol. 113, 1918, p. 471.

[4] D. R. Herschbach, H. S. Johnston, K. S. Pitzer and R. E. Powell, "Comparison of the Arrhenius Frequency Factors (A) of Some Gas-Phase Reactions," Journal of Chemistry Physics, Vol. 25, 1956, p. 73. 